\title{
Chemically Fueled Plasmon Switching of Gold Nanorods by Single-Base Pairing of Surface-
}

\section{Grafted DNA}

Lan Zhang, ${ }^{\dagger}$ Chenlin Zhao, ${ }^{\dagger}$ Yao Zhang,${ }^{\dagger}$ Luyang Wang, ${ }^{\dagger}$ Guoqing Wang, $,{ }^{\dagger}, \dagger, \S$

Naoki Kanayama, ${ }^{*} \|$ Tohru Takarada, ${ }^{*}$, Mizuo Maeda, ${ }^{\star}, \|$ and Xingguo Liang ${ }^{\dagger, \S}$

${ }^{\dagger}$ College of Food Science and Engineering, Ocean University of China, 5 Yushan Road, Qingdao 266003, China.

${ }^{\ddagger}$ Bioengineering Laboratory, RIKEN Cluster for Pioneering Research, 2-1 Hirosawa, Wako, Saitama 351-0198, Japan.

${ }^{\S}$ Laboratory for Marine Drugs and Bioproducts, Pilot National Laboratory for Marine Science and Technology (Qingdao), Qingdao 266237, China "Graduate School of Medicine, Science and Technology, Shinshu University, 4-7-1 Wakasato, Nagano-shi, Nagano 380-8553, Japan.

E-mail: gqwang@ouc.edu.cn (G.W.); ttkrd@ riken.jp (T.T.) 


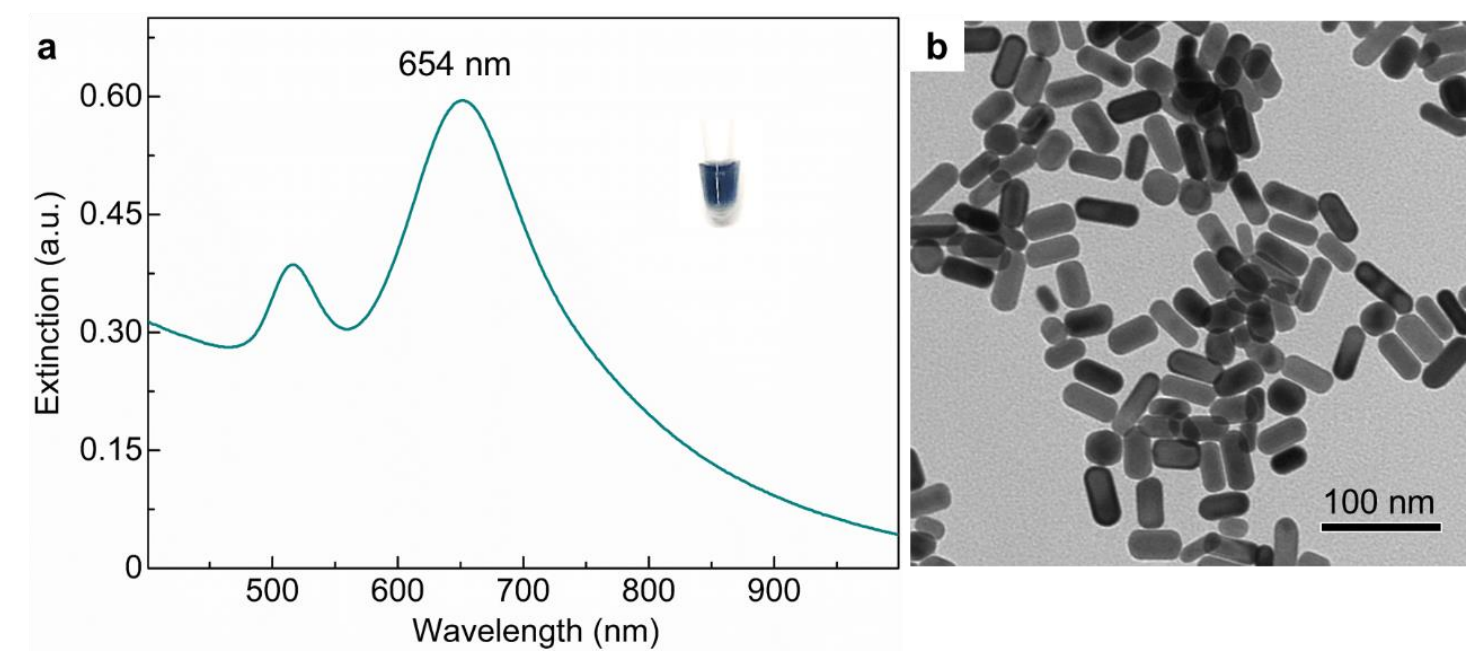

Figure S1 Characterization of the bare AuNRs synthesized in this study. (a) Extinction spectrum and digital photograph for the dispersion of the bare AuNRs. (b) Typical TEM image of the bare AuNRs. 
a
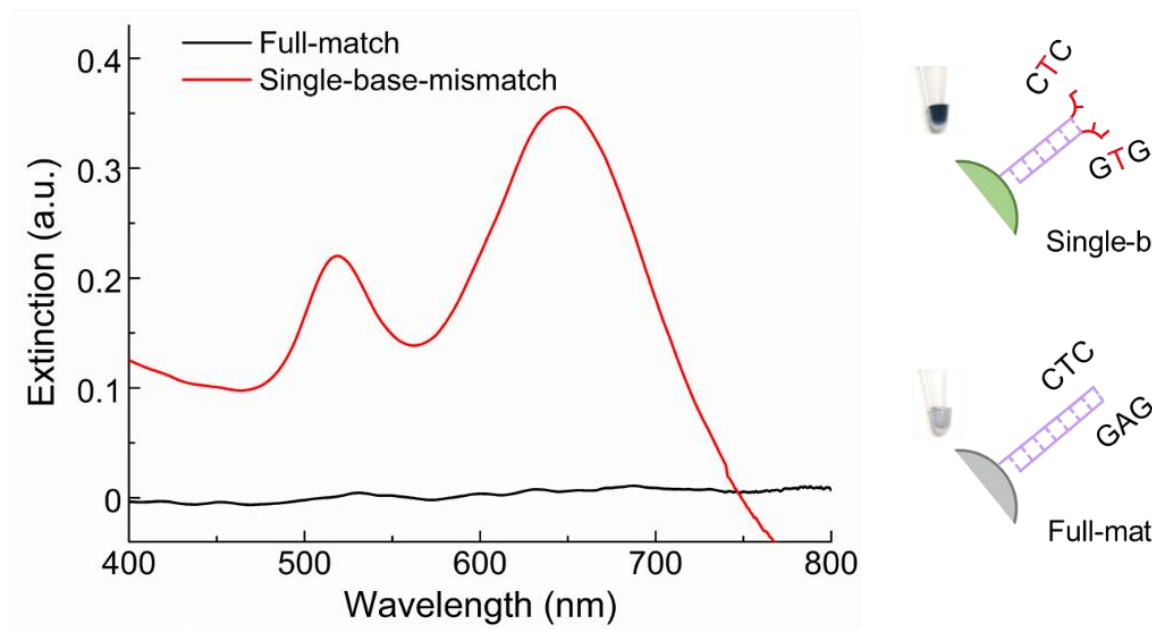

Single-base-mismatch

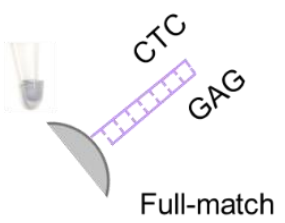

b
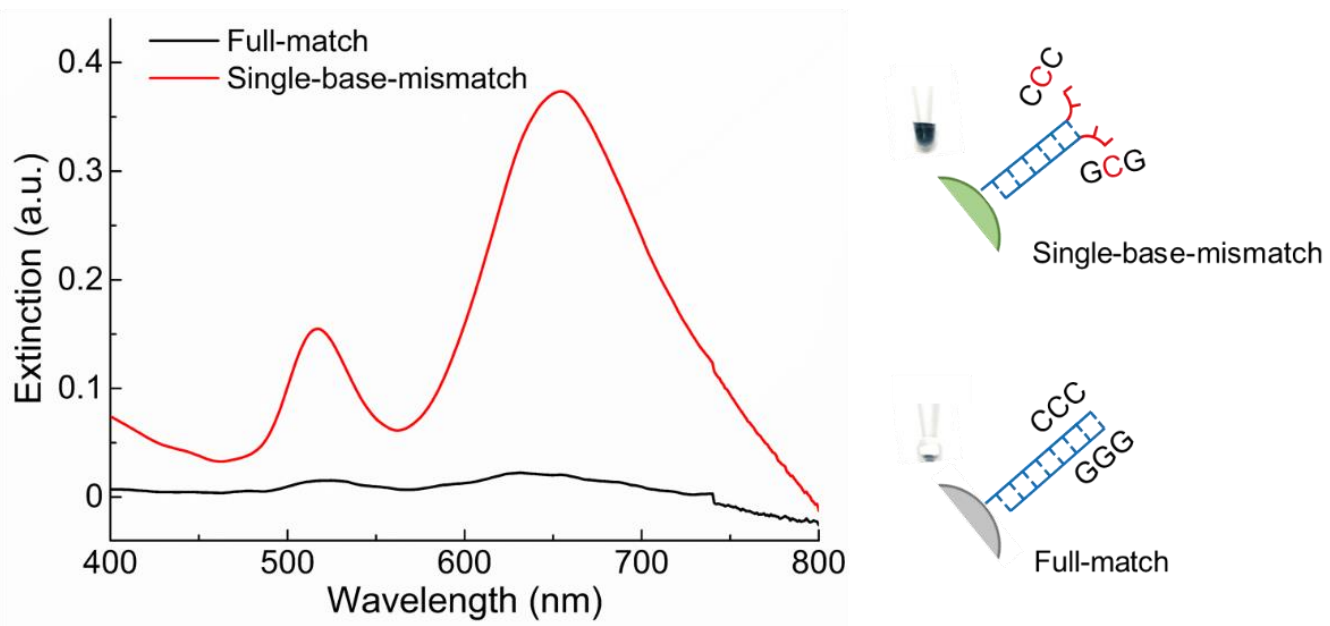

Figure S2 Non-cross-linking aggregation and terminal-mismatch-induced dispersion of dsDNAAuNRs. Each set shows the extinction spectra, the digital photographs and the schematics for (a) the DNA1-AuNR with com1 (full-match) or mis1 (single-base-mismatch) and (b) the DNA2AuNR with com2 (full-match) or mis2 (single-base-mismatch) in the presence of $0.8 \mathrm{M} \mathrm{NaNO}_{3}$. 


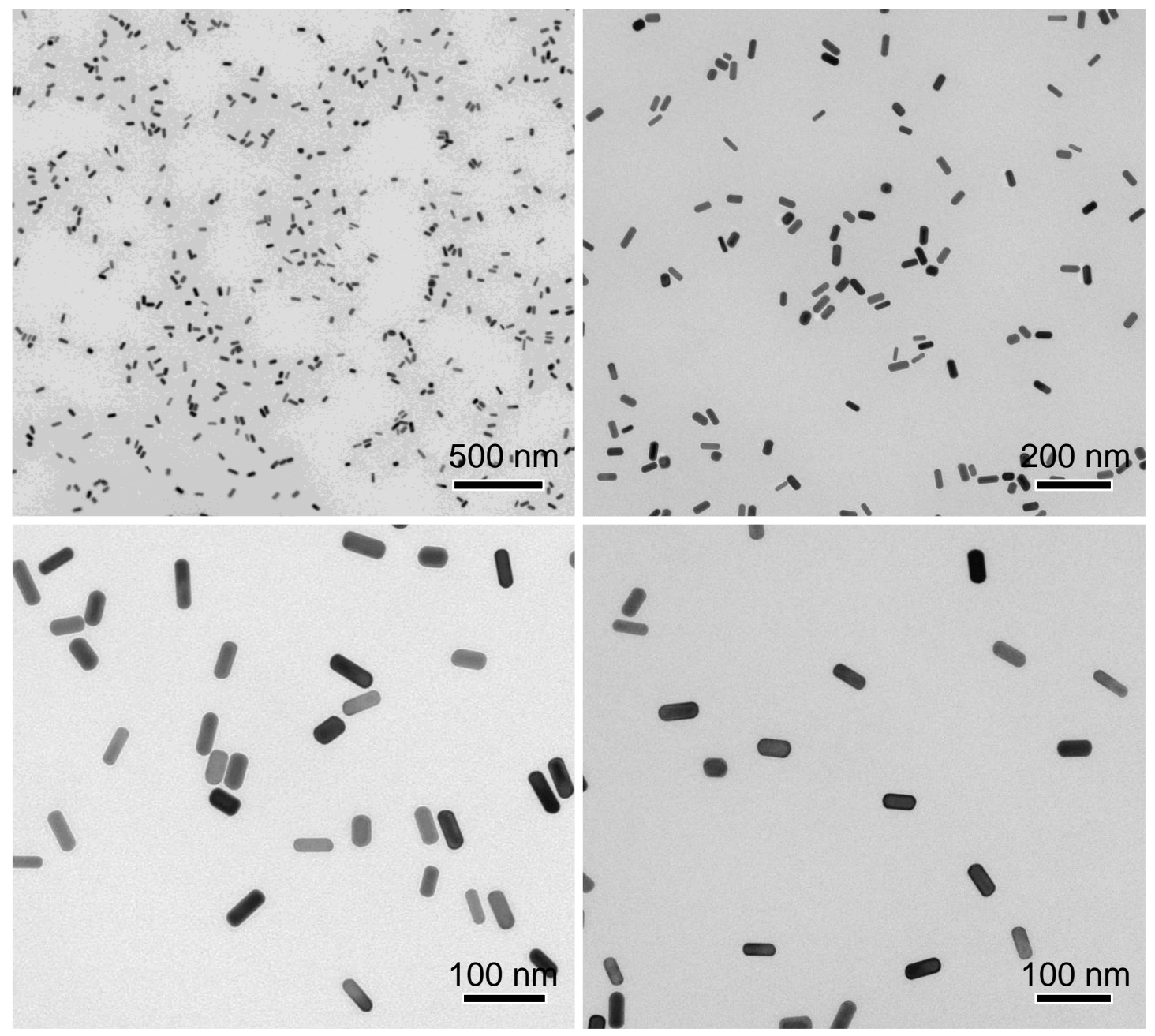

Figure S3 Typical TEM images for the dispersion of the AuNRs after the surface-modification with DNA1. The ssDNA-AuNRs were dispersed in $10 \mathrm{mM}$ HEPES buffer containing $0.8 \mathrm{M} \mathrm{NaNO}_{3}$. 


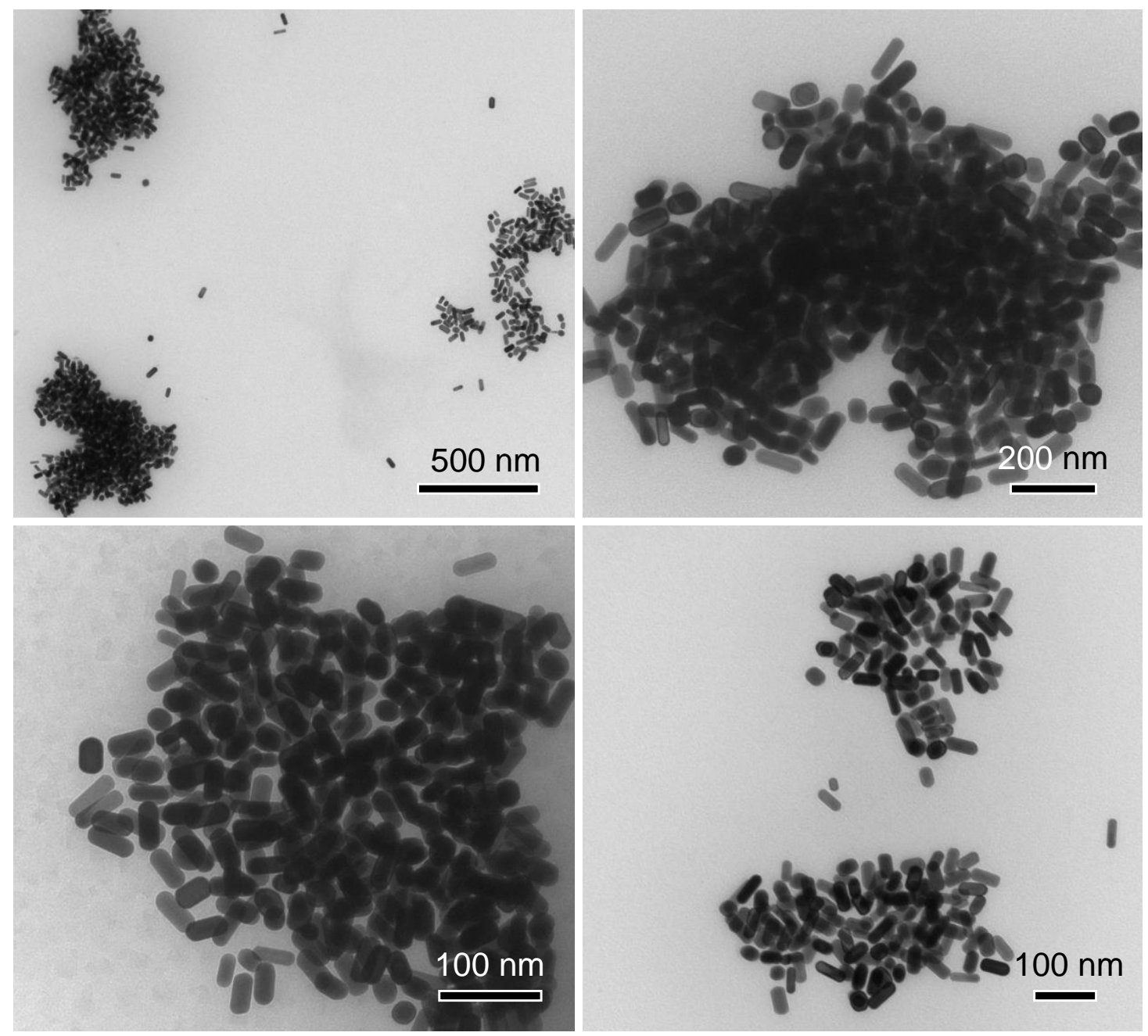

Figure S4 Typical TEM images for the non-cross-linking aggregation of the dsDNA-AuNRs having the $\mathrm{T}-\mathrm{T}$ mismatch $(2 \mathrm{nM})$ with $\mathrm{Hg}\left(\mathrm{NO}_{3}\right)_{2}(2 \mu \mathrm{M})$ in $10 \mathrm{mM}$ HEPES buffer containing $0.8 \mathrm{M} \mathrm{NaNO}_{3}$. 


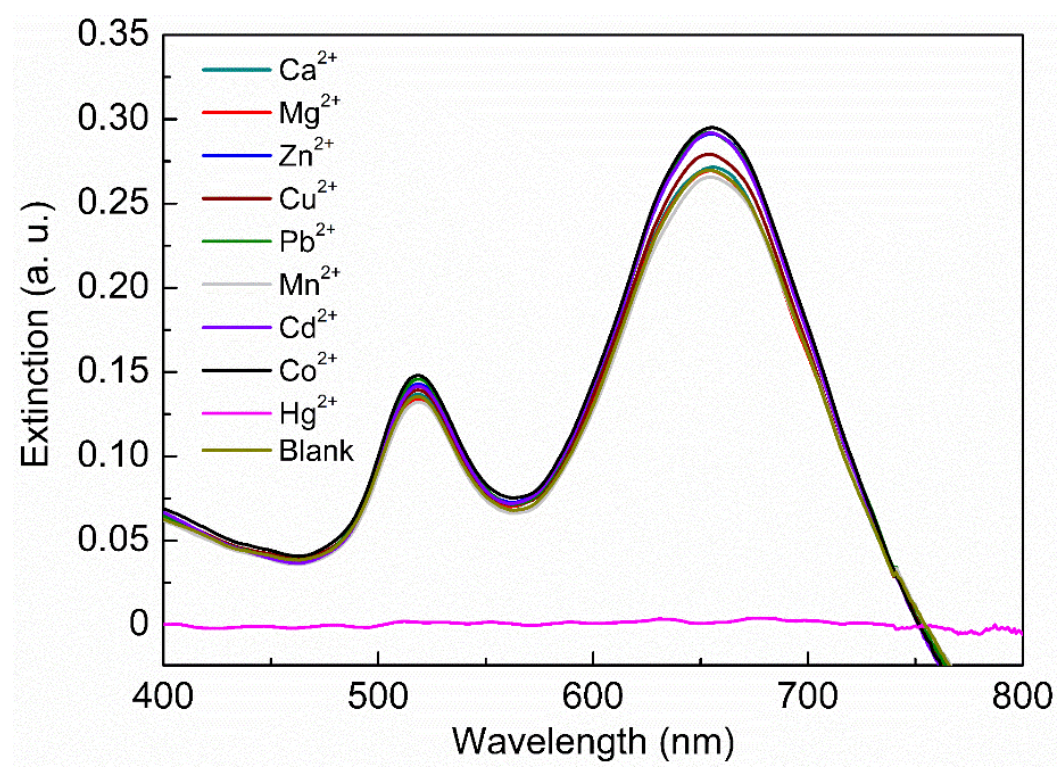

Figure S5 Extinction spectra for the dispersion/aggregation of the dsDNA-AuNRs having the T-T mismatch $(2 \mathrm{nM})$ in the presence of various salts $(2 \mu \mathrm{M})$, including $\mathrm{CaCl}_{2}, \mathrm{MgCl}_{2}, \mathrm{ZnCl}_{2}, \mathrm{CuSO}_{4}$, $\mathrm{Pb}\left(\mathrm{NO}_{3}\right)_{2}, \mathrm{MnCl}_{2}, \mathrm{CdCl}_{2}, \mathrm{CoCl}_{2}$ and $\mathrm{Hg}\left(\mathrm{NO}_{3}\right)_{2}$, in $10 \mathrm{mM}$ HEPES buffer containing $0.8 \mathrm{M} \mathrm{NaNO}_{3}$. 


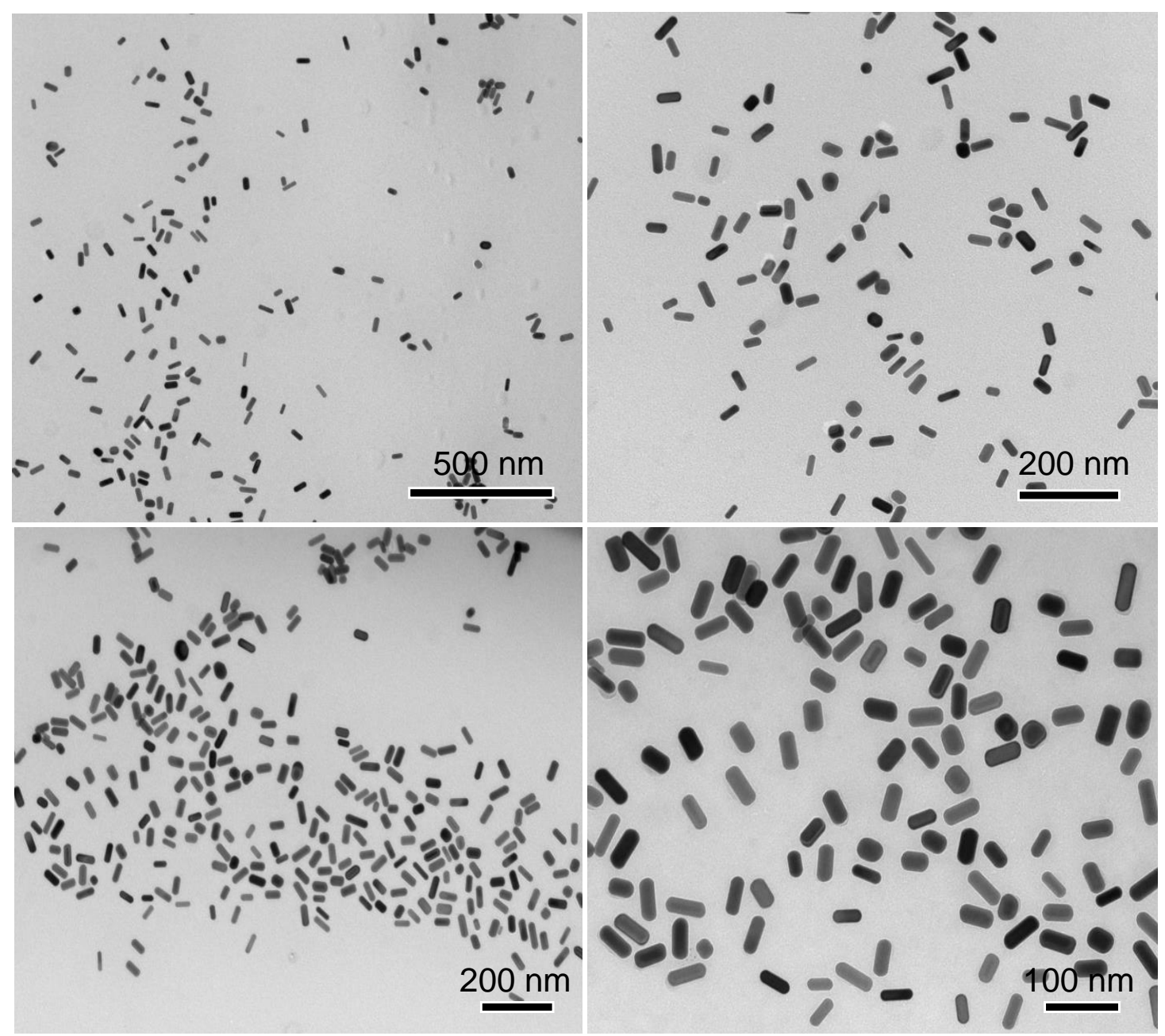

Figure S6 Typical TEM images for the dispersion of the dsDNA-AuNRs having the $\mathrm{T}-\mathrm{Hg}-\mathrm{T}$ base pair $(2 \mathrm{nM})$ with Cys $(2 \mu \mathrm{M})$ in $10 \mathrm{mM}$ HEPES buffer containing $0.8 \mathrm{M} \mathrm{NaNO}_{3}$. 


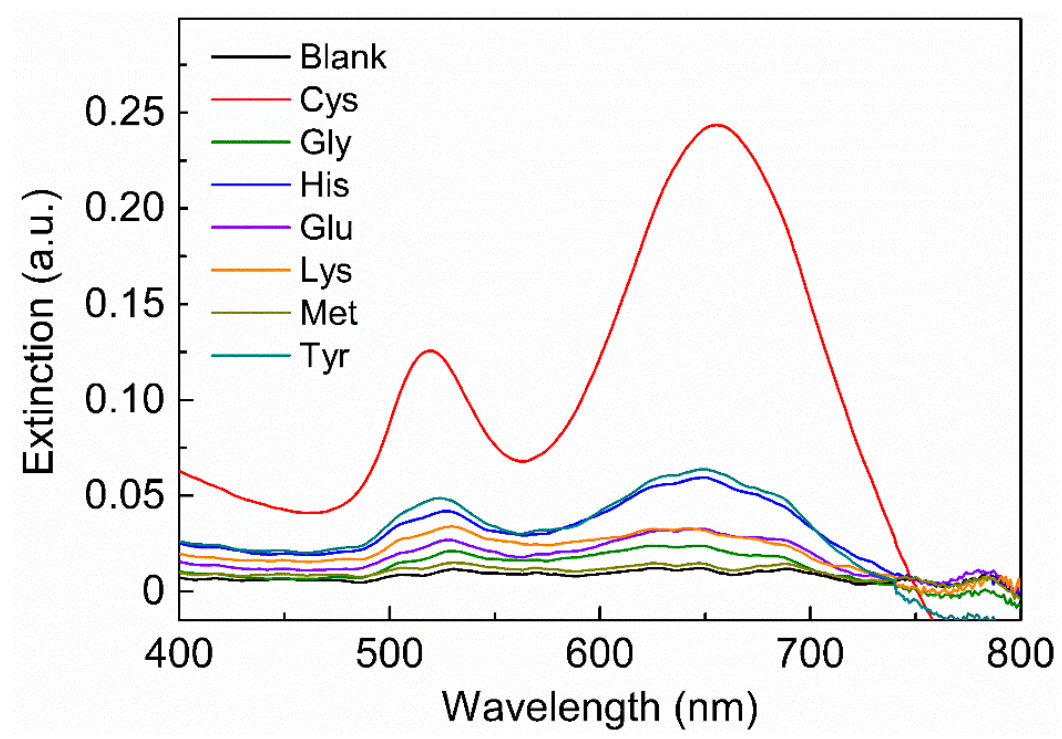

Figure S7 Extinction spectra of the dsDNA-AuNRs having the T-Hg-T base pair $(2 \mathrm{nM})$ upon the introduction of various amino acids $(2 \mu \mathrm{M})$, including Cys, Gly, His, Glu, Lys, Met, and Tyr, in 10 mM HEPES buffer containing $0.8 \mathrm{M} \mathrm{NaNO}_{3}$.

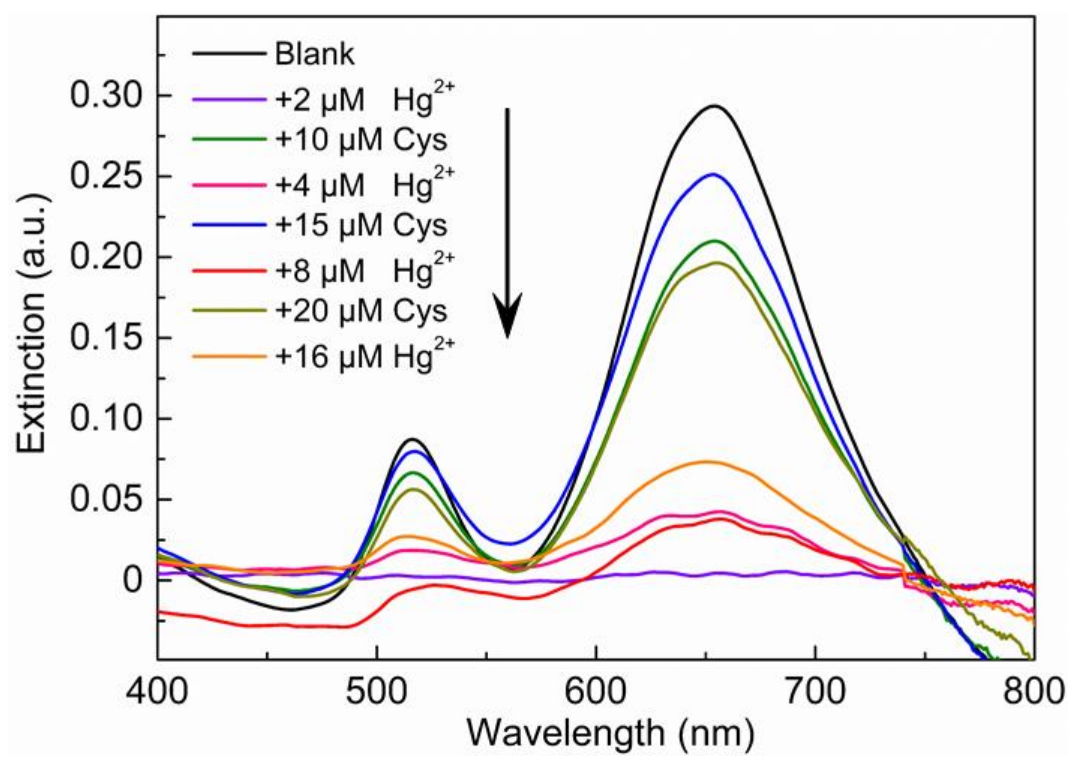

Figure S8 Extinction spectra of the dsDNA-AuNRs having the T-T mismatch $(2 \mathrm{nM})$ upon the consecutive and alternate introduction of $\mathrm{Hg}\left(\mathrm{NO}_{3}\right)_{2}$ and Cys in $10 \mathrm{mM}$ HEPES buffer containing $0.8 \mathrm{M} \mathrm{NaNO}_{3}$ at room temperature. 


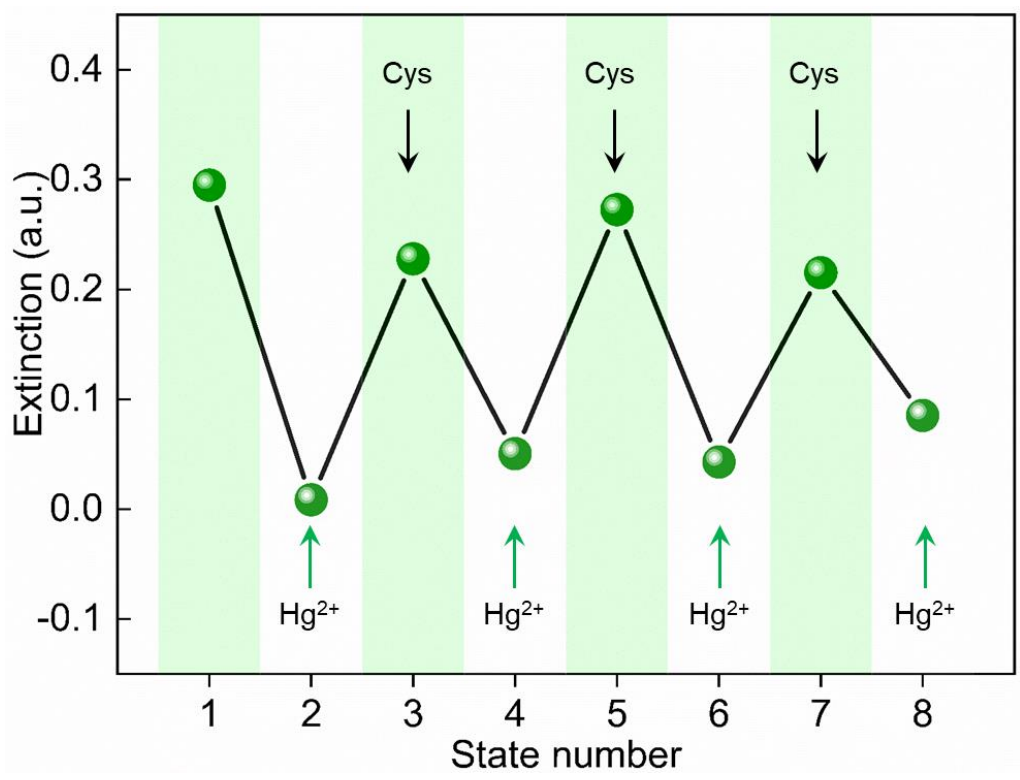

Figure S9 Cycling of normalized extinction intensity at $650 \mathrm{~nm}$ of the dsDNA-AuNRs having the $\mathrm{T}-\mathrm{T}$ mismatch $(2 \mathrm{nM})$. The concentration of $\mathrm{Hg}\left(\mathrm{NO}_{3}\right)_{2}$ in the state $2,4,6$ and 8 was $2 \mu \mathrm{M}, 4 \mu \mathrm{M}, 4$ $\mu \mathrm{M}$ and $8 \mu \mathrm{M}$, respectively. The concentration of Cys in the state 3,5 and 7 was $1 \mu \mathrm{M}, 2 \mu \mathrm{M}$ and 4 $\mu \mathrm{M}$, respectively.

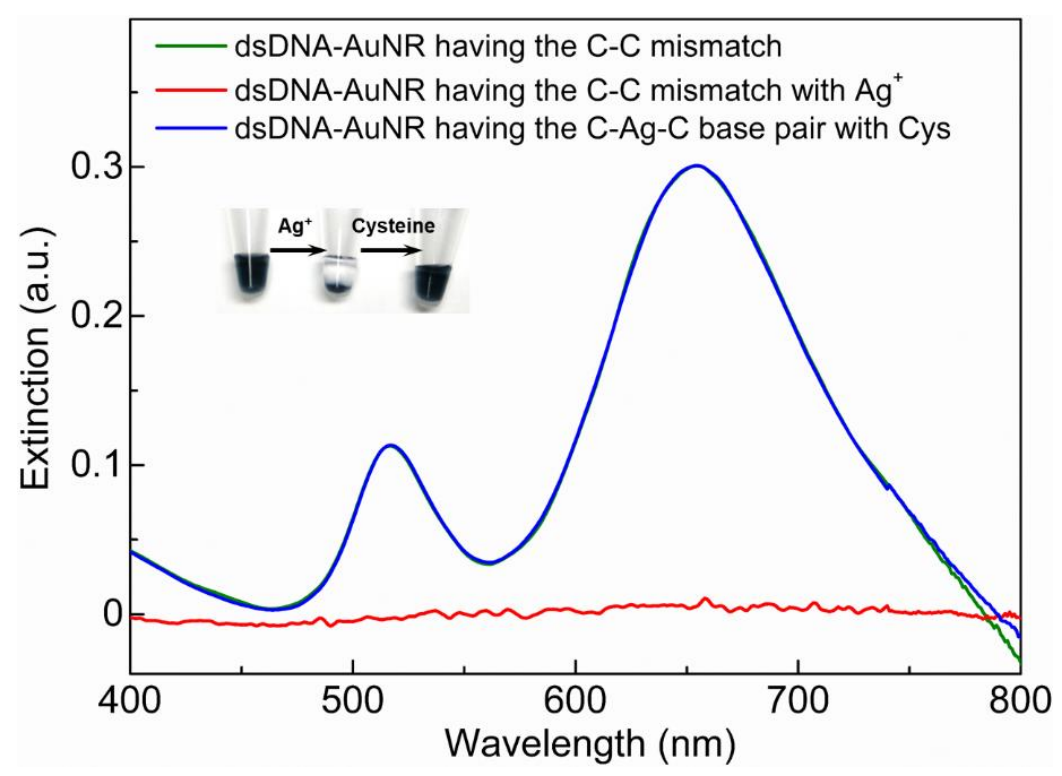

Figure S10 Extinction spectra of the dsDNA-AuNRs having the $\mathrm{C}-\mathrm{C}$ mismatch, the $\mathrm{AgNO}_{3}(2$ $\mu \mathrm{M})$-treated dsDNA-AuNRs having the $\mathrm{C}-\mathrm{C}$ mismatch and the Cys $(2 \mu \mathrm{M})$-treated dsDNA-AuNRs having the $\mathrm{C}-\mathrm{Ag}-\mathrm{C}$ base pair. The corresponding photographs are also shown. 


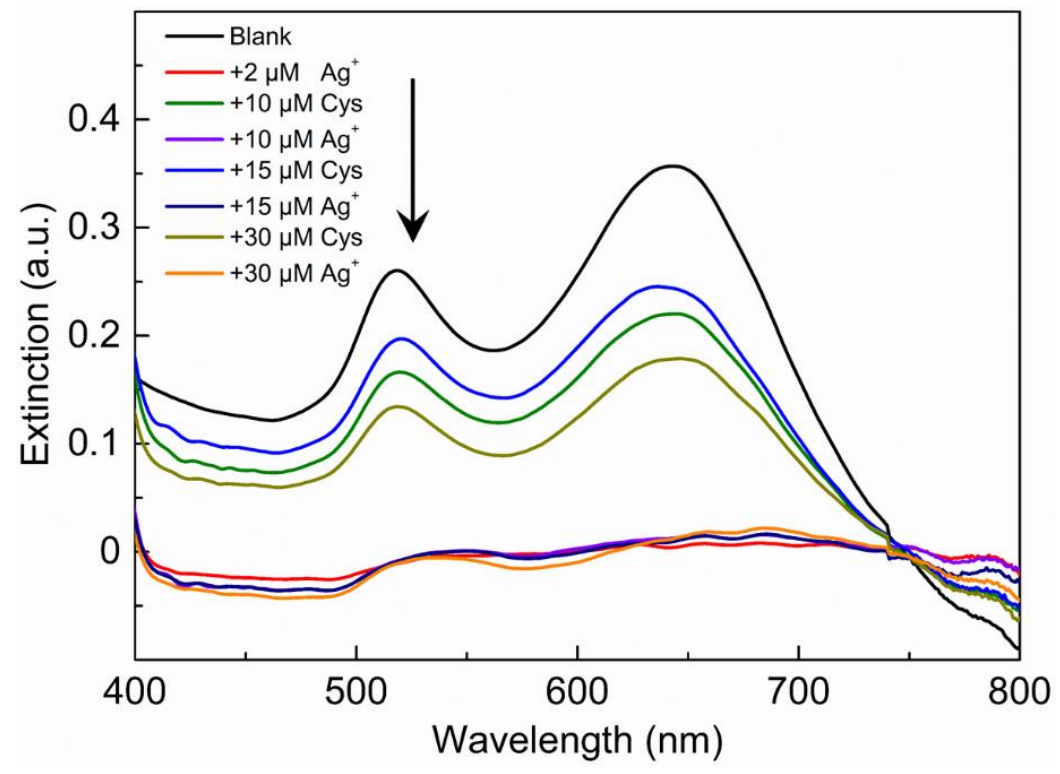

Figure S11 Extinction spectra of the dsDNA-AuNRs having the C-C mismatch ( $2 \mathrm{nM})$ upon the consecutive and alternate introduction of $\mathrm{AgNO}_{3}$ and Cys in $10 \mathrm{mM}$ HEPES buffer containing 0.8 $\mathrm{M} \mathrm{NaNO}_{3}$ at room temperature.

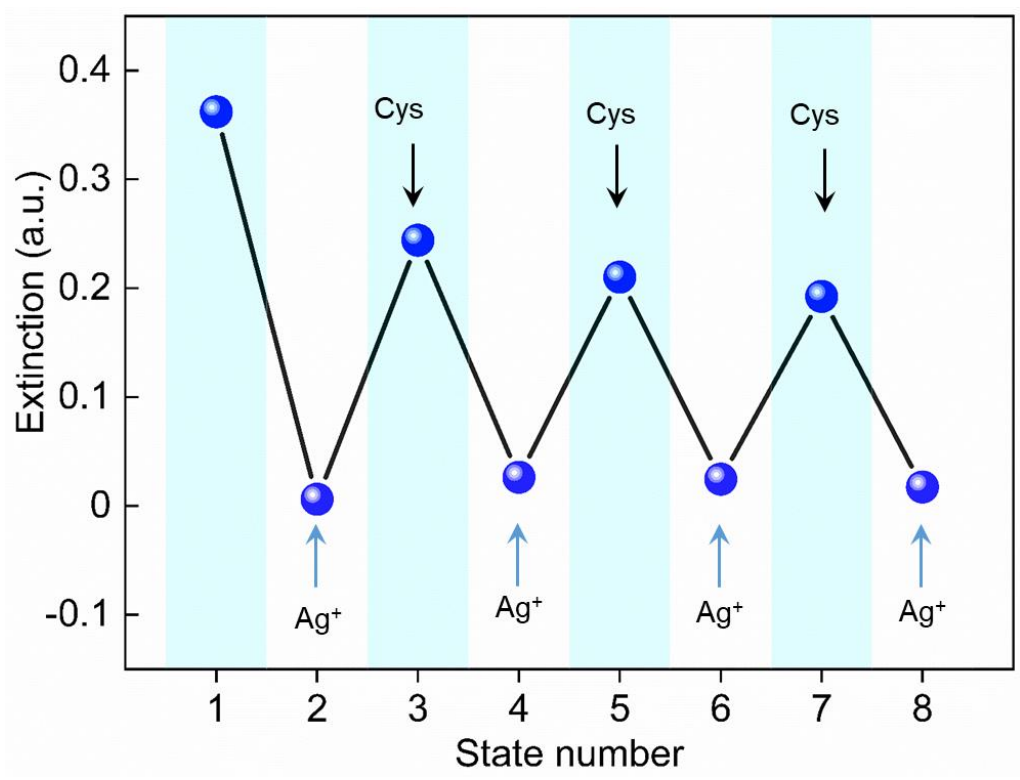

Figure S12 Cycling of normalized extinction intensity at $650 \mathrm{~nm}$ of the dsDNA-AuNRs having the $\mathrm{C}-\mathrm{C}$ mismatch $(2 \mathrm{nM})$. The concentration of $\mathrm{AgNO}_{3}$ in the state 2, 4, 6 and 8 was $2 \mu \mathrm{M}, 4 \mu \mathrm{M}, 8$ $\mu \mathrm{M}$ and $22 \mu \mathrm{M}$, respectively. The concentration of Cys in the state 3, 5 and 7 was $4 \mu \mathrm{M}, 8 \mu \mathrm{M}$ and $16 \mu \mathrm{M}$, respectively. 